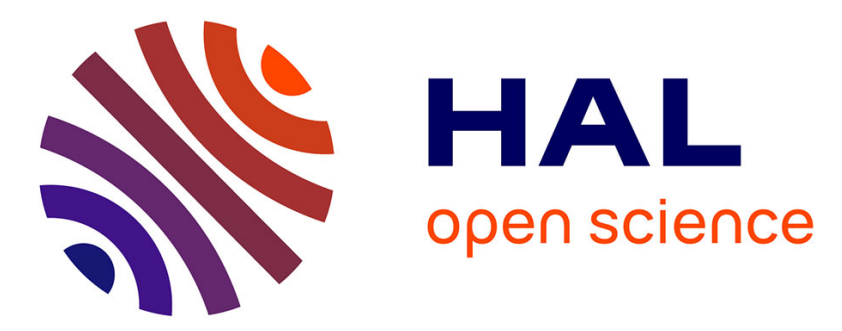

\title{
Practical aspects of material data bases and expert systems for high-temperature corrosion and coatings in gas turbines
}

Henry Bernstein

\section{- To cite this version:}

Henry Bernstein. Practical aspects of material data bases and expert systems for high-temperature corrosion and coatings in gas turbines. Journal de Physique IV Proceedings, 1993, 03 (C9), pp.C91001-C9-1012. 10.1051/jp4:19939103 . jpa-00252345

\section{HAL Id: jpa-00252345 https://hal.science/jpa-00252345}

Submitted on 1 Jan 1993

HAL is a multi-disciplinary open access archive for the deposit and dissemination of scientific research documents, whether they are published or not. The documents may come from teaching and research institutions in France or abroad, or from public or private research centers.
L'archive ouverte pluridisciplinaire HAL, est destinée au dépôt et à la diffusion de documents scientifiques de niveau recherche, publiés ou non, émanant des établissements d'enseignement et de recherche français ou étrangers, des laboratoires publics ou privés. 


\title{
Practical aspects of material data bases and expert systems for high-temperature corrosion and coatings in gas turbines(*)
}

\author{
Henry L. Bernstein
}

Southwest Research Institute, 6220 Culebra Road, P.O. Drawer 28510, TX 78228-0510, San Antonio, Texas, U.S.A.

\begin{abstract}
High-temperature environmental attack often limits the useful service life of the hot section components in gas turbines, for aircraft, marine and industrial applications. Hightemperature coatings are mandatory to obtain acceptable service life, but the life of these coatings often determines the refurbishment intervals. This paper addresses the use of computerized data bases and expert systems for high-temperature corrosion and high-temperature coatings, which have not always been useful for other material problems. The principal problems with material data bases are assessing the quality of the data; describing the materials, test conditions and test results; as well as the more common problems of data retrieval, correction of errors, and updating of data. Expert systems have generally not achieved expert performance, but are useful for people having less expertise than the program. Several expert systems are discussed including one that is currently being used by electric utilities to select high-temperature coatings for ind ustrial gas turbine blades. Finally, in developing data bases and expert systems, the rapid prototyping process is recommended, along with a careful consideration of the end users, the available data and the available expertise.
\end{abstract}

\section{Introduction.}

Computerized systems applied to material problems have been of significant interest for the past 10 to 15 years. An important portion of this interest has been directed to material data bases and expert systems. Some effort, but not much, has gone into data bases and expert systems for high-temperature attack and high-temperature coatings.

It is the purpose of this paper to briefly review the areas of material data bases and expert systems, and especially how these programs are applicable to material problems involving high-temperature attack and coatings for gas turbine engines. Existing systems will be reviewed to illustrate the concepts and potential problems.

This paper is written for a non-programmer not familiar with computers, but who is considering developing a computer program or who is involved in the technical oversight of a program development effort. The paper attempts to provide practical advice on the development of these programs and to point out some of the potential pitfalls. In this regard, the paper may be of value to persons experienced in computers and programming.

HIGH-TEMPERATURE ATTACK AND COATINGS FOR GAS TURBINE ENGINES. - Gas turbine vanes and blades must be coated to resist high-temperature attack in aircraft, marine and industrial engines [1,2]. The life of these coatings is frequently the limiting factor in the durability of the

(*) Keynote lecture. 
high-temperature blades and vanes, and determines when they must be removed in order to renew the coating. Although the most attention to coatings is required for first stage blades and vanes, latter stages are often coated as well.

High-temperature attack in gas turbines involves high-temperature oxidation, lowtemperature hot corrosion and high-temperature hot corrosion. In addition, a form of attack called gas phase embrittlement has been reported in laboratory experiments.

A wide variety of high-temperature coatings are used in gas turbines. The most common ones are aluminide coatings, although chromium coatings are used at lower temperatures. The aluminide coatings are frequently modified by the addition of $\mathrm{Cr}, \mathrm{Si}, \mathrm{Pt}, \mathrm{Rh}$ or $\mathrm{Y}$ to improve their resistance to high-temperature attack. Overlay coatings are used to provide greater resistance to attack, especially for industrial gas turbines. These coatings typically consist of $\mathrm{Co}, \mathrm{Ni}$, or a combination of the two, in conjunction with $\mathrm{Cr}, \mathrm{Al}$ and $\mathrm{Y}$. Sometimes $\mathrm{Si}$, $\mathrm{Ta}, \mathrm{Hf}$ or $\mathrm{Zr}$ is added. More recently, duplex coatings, consisting of a combination of overlay and aluminide coatings, have been introduced for industrial gas turbines. Finally, thermal barrier coatings consisting of a ceramic layer over an overlay coating have been used for a number of years to lower base metal temperatures of combustor hardware, and have recently been applied to vanes.

There are a number of different application methods for coatings. The most common method is pack cementation, which has been modified for above the pack, pulsed gas, and pumped gas in order to coat cooling passages. Overlay coatings are applied by a variety of methods, although the low pressure plasma spray process is the most common one for high quality coatings. Air plasma spray processes and argon shrouded plasma spray processes are in use, with the argon shrouded process able to produce high quality coatings under the right conditions. Electron beam, pressure vapor deposition processes are also used for overlay coatings, as well as for some thermal barrier coatings.

High-temperature coatings and high-temperature attack are complex topics and are not entirely understood. This is due to the complex chemical reactions that occur at high temperatures and significant effects on the reactions from temperature and small chemical changes in the metal and gaseous environment. There are a large number of commercial coatings available and a number of different application methods, which influence the final properties of the coatings. There is no one coating that is resistant to all types of high-temperature attack.

\section{Data bases.}

Data bases are used for storing and retrieving a wide variety of information. There are three common types of data bases: flat-file data base, hierarchical data base, and relational data base [3]. A flat-file data base is the simplest, and perhaps most common, form of a data base.

An address list is an example of a flat-file data base. The data base file is composed of fields and records. The fields are where the name, address, city, state, zip and phone number of a person are stored. The record is composed of all the information on a single person that is in these fields. However, the application of flat-file data bases is limited by the inability to store and relate multiple data sets.

A hierarchical data base can be used to maintain complex data sets. A hierarchical data base consists of numerous files organized in a tree-like structure. An example of their use is for part lists of complex assemblies in machinery. However, hierarchical data bases are difficult to modify because the structure of the data base is very difficult to change once it has been established. 
Most material data bases are relational data bases because of their power and flexibility. A relational data base is composed of a group of flat-file data bases, which are related by the use of common fields. These relations can be defined and redefined to relate existing files as new requirements are identified. Furthermore, new fields and files can be easily added or deleted as needed.

2.1 MATERIAL DATA BASES. - Computerization of material data bases is an active field with many data bases developed and in use [4-6] ( $\left.{ }^{1}\right)$. ASTM Committee E-49 on Computerization of Material Property Data has developed three standards for material data bases and is actively developing additional standards $\left({ }^{2}\right)$.

For the purposes of this paper, material data bases will be divided into two types - material properties and material test results - although other divisions could be made. The material property data base gives a single value for each property of interest. These properties have been determined from materials test data and analyzed separately from the computerized data base. This is the type of data base in handbooks of material properties.

The material test results data base is used to store and retrieve material test data, and may be supplemented by properties determined by others or from those reported in handbooks. It is a richer data base than the materials property data base, but it is also harder to develop and more complex to use.

One of the principal difficulties of all material data bases is describing the material in enough detail to distinguish the features of importance. ASTM Standard E1314 suggests 37 fields to identify an alloy, with 18 considered essential. These fields include information on specifications, chemical composition, processing and product geometry. For the test results data base, this description may be necessary to understand the variation in the test results. This description is less critical for the material property data base, where it may be sufficient to describe the material similar to that used in vendor specifications.

The test results data base has two other difficulties largely absent from the materials properties data base - quality of the data and describing the test conditions and test results. Someone must make a judgement as to quality of the test results, particularly for data taken from the literature. Standards for making these judgements are under discussion in ASTM Committee E-49.

A large amount of information may be needed to describe the test conditions and results. ASTM Standard E1313 recommends 67 fields for describing one $K_{\mathrm{IC}}$ fracture toughness test. Clearly, all the information may not be readily available, especially for data from the literature. Furthermore, variation in reporting of test results from lab to lab can cause difficulty in comparing data.

2.2 DATA BASES FOR HIGH-TEMPERATURE ATTACK AND PROTECTIVE COATINGS. - Few data bases, apart from proprietary company data bases, exist for high-temperature attack and high-temperature coatings. Streiff and co-workers have been developing such a data base [7], and its current status is reported in this conference. Corrosion data bases, both computerized and in books, are available, usually of the material property type of data base. The most common ones are tables giving the resistance to attack as a function of environment and

( $\left.{ }^{1}\right)$ Paper data bases in the forms of books and reports have been in use for decades.

$\left({ }^{2}\right)$ ASTM Standards E1313-90, Standard Guide of Development of Standard Data Records for Computerization of Material Property Data; E1314-89, Standard Practice for Structuring Terminological Records Relating to Computerized Test Reporting and Materials Designation Formats; and E133890, Standard Guide for the Identification of Metals and Alloys in Computerized Material Property Data Bases. 
temperature, and reported in qualitative terms, such as poor, fair, good and excellent. This level of reporting is insufficient for gas turbines because all materials are attacked, and it is the rate of attack that is critical.

For the materials test results type of data base, high-temperature attack and hightemperature coatings are particularly difficult to handle because of the problems inherent in the data itself. High-temperature coatings are particularly difficult to characterize as to their condition. The parameters controlling their application are frequently proprietary, and may not always be known with certainty by the coater, such as variations in pack composition and temperature. Also important is the base metal composition and details of surface preparation, which may not always be sufficiently described.

Burner rig tests are performed under a wide variety of operating conditions, but are difficult to control, especially the temperature. In hot corrosion tests, defining the actual corrosion conditions is not always easy, so comparing data from different laboratories can be difficult and confusing. Test results from actual gas turbines are especially difficult to compare due to the numerous engine, fuel and location variables inherent in engine operation.

Finally, describing the condition of the coating or metal after the test poses challenges, since different criteria are used to determine the level of attack. For high-temperature coatings, the parameter most often reported is coating thickness or depth of attack, but maximum and average values must be distinguished. For aluminide coatings, it has been shown that the aluminum content of the coating is crucial because once the aluminum level falls to the regime of a predominantly gamma-prime phase, the coating is rapidly penetrated. Prior to this loss of aluminum, the coating thickness remains relatively constant $[8,9]$.

Overcoming the above problems inherent in the data requires standardization of test methods and reporting of test results. In the absence of these standards, substantial effort on the part of both the programmer and the interpreter of the data is required. Each set of test data must be carefully evaluated by a skilled interpreter, who may not always have the necessary time or patience.

\section{Expert systems.}

Expert systems are a branch of artificial intelligence. Artificial intelligence is concerned with trying to make computers think, or reason, such that their behavior would be considered as intelligent if it was done by a person [10]. Expert systems attempt to make the computer "think", or reason, such that their answers would be considered as coming from an expert [11]. Sometimes the term "Knowledge-based systems" is used instead of Expert Systems to indicate that the answers are based upon a body of knowledge, but may not have the level of skill provided by an expert $\left({ }^{3}\right)$.

In actual use, the term "expert system" has been applied to a wide variety of software functioning at different levels of expertise. Consequently, the term "expert system" has lost its specific technical meaning. As used today, "expert system" can refer to any software that explicitly uses knowledge to make decisions or recommendations, and has even been applied to computational of data base programs that use expert programming languages to write the program and the user interface.

$\left({ }^{3}\right)$ Expert systems are actually a subset of knowledge-based systems. 
3.1 STRUCTURE AND DEVELOPMENT OF EXPERT SYSTEMS. - The structure of an expert system consists of a user interface, a knowledge base and an inference engine, as shown in figure 1. The user interface obtains the input from the user, usually from a question-answer type of dialog, and gives the user the answers. The knowledge base contains a representation of the knowledge acquired from the experts. The most common representation of this knowledge is by facts and rules $\left({ }^{4}\right)$. The inference engine performs the reasoning and controls the execution of the program. The separation of the knowledge into a separate portion of the computer code is the unique feature of expert, or knowledge-based, systems that distinguishes these programs from other, conventional computer programs. Another distinguishing feature of expert systems is the ability to display and trace the reasoning used to arrive at the decision.

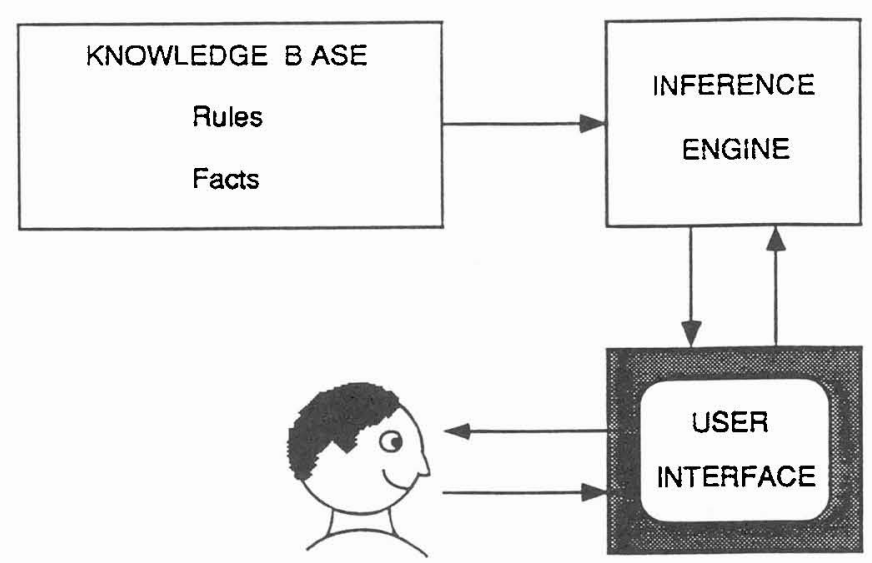

Fig. 1. - Structure of an expert system.

The most common form of expert system is a rule-based system, which refers to how the knowledge is represented. Other representation schemes, such as frames, semantic nets, scripts, and logic-based systems, are also in use. Many expert systems are combinations of these different approaches, and are called hybrid systems. Descriptions of these different systems can be found in books on expert systems $\left({ }^{5}\right)$. The actual representations chosen for a particular application depend upon the problem to be solved, the nature of the knowledge to be represented in the computer, and the hardware to be used. Expert systems for microcomputers have generally used rule-based systems because the other systems usually require more memory than has been available in microcomputers.

Expert systems can be written using special programming languages called expert system development tools or shells. Alternatively, expert systems can be written with more general purpose programming languages such as LISP, C or FORTRAN.

In a rule-based system the knowledge is expressed as a series of if-then statements. These rules are combined, or chained, to provide a reasoning sequence from initial problem to

$\left({ }^{4}\right)$ The term "knowledge representation" refers to how the knowledge is expressed in the computer program.

$(5)$ Rule-based systems will be briefly discussed in this paper. To be understandable, the other systems require a more lengthy discussion than can be given in this paper. 
final conclusions. This combination can be done in two ways. One can start with the facts and derive the conclusions; i.e., if $A$ then $B$, if $B$ then $C$, if $C$ then $D$ and not $E$. This is referred to as forward chaining. Alternatively, one can start with the conclusions, and see if the facts will support the conclusions; i.e. assume $\mathrm{E}$, which means not $\mathrm{C}$, which means not $\mathrm{B}$, which means not $\mathrm{A}$, but $\mathrm{A}$ is true so $\mathrm{E}$ must be false. This is referred to as backward chaining. Backward chaining is useful for some types of problems such as determining if someone is your ancestor, since tracing out all of a potential ancestor's children and grandchildren, etc., may be an impossibly large undertaking. Forward chaining is more appropriate when a large amount of data is first collected, which is then used to draw conclusions.

Expert systems can work with non-quantitative, or subjective, information and can work when information is missing (although certain information is usually mandatory). Expert systems are good for poorly defined problems where there are a variety of factors that must be considered, such as deciding what car to buy. Various reasoning mechanisms, including Baysean decision theory, fuzzy logic, etc., are used to support the decision-making when available information is inexact or incomplete.

Expert systems are developed by interviewing experts and translating their knowledge into a representation of that knowledge in the computer program. The person who performs the interviews and develops the knowledge representation for the computer is called a "knowledge engineer", and may or may not actually write the computer code. Typically, the knowledge engineer is a computer programmer trained in this type of interviewing, although individuals trained in the technical area and familiar with computer programming may perform this function as well. The program is tested by the experts who judge the accuracy of the results.

Expert systems are time consuming and expensive to develop. Most of this time and expense is spent developing the knowledge base. Obtaining the expertise from the human expert is an iterative process because the expert is unable to think of every conceivable situation during one interview. Furthermore, human experts may not always be cooperative, or able to systemize their knowledge so that it can be expressed in a computer program. It is the author's experience that the best knowledge engineers are individuals trained in the technical area of interest and who are familiar with computer programming. They are able to talk with the experts in their terms and ask meaningful questions, yet still formulate the knowledge in terms that can be programmed into a computer $\left({ }^{6}\right)$. It can be very frustrating to an expert to try to explain a lifetime of accumulated knowledge to someone who has absolutely no idea or appreciation of what is being talked about.

Once developed and in-use, one should anticipate the need to make changes in the expert system, due to new knowledge becoming available, the need to address questions that were not originally considered, and changes to the configuration and operation of the equipment that the expert system is addressing. In the area of gas turbines, such changes are needed to handle new engines, materials, coatings, higher temperature operation and the desire for more refined recommendations.

3.2 STATUS OF EXPERT SYSTEMS. - In general, expert systems have failed to achieve performance equivalent to that of an expert. This failure is attributed to the complexity of actual problems. However, this lack of success should not be surprising when one considers chess programs, which can be considered a class of expert systems. Despite 30+ years of development, human experts still beat the best chess programs, even though all the facts and rules are known, which is hardly the case with most situations.

$\left({ }^{6}\right)$ For larger systems, a software engineer is also needed to assist in the knowledge representation. 
Expert systems are usually used by people having less expertise than the program, or by experts when the facts and rules are known, but the problem is sufficiently complex that a computer is of great assistance. One of the most successful applications of expert systems has been XCON (sometimes called R1), an expert system in use by Digital Equipment Corp. (DEC) to configure their VAX computer systems [12]. XCON determines the necessary component modifications, generates diagrams showing the spatial and logical arrangements of the components, determines the cable lengths, etc. For this expert system, there is complete knowledge of the facts and rules. Another expert system, called PROSPECTOR, has successfully determined mineral deposits in both known and unknown areas [13], using geological information and measurements. The system took more than 30 person-years to develop over a period from 1974 to 1983 , largely due to the extensive knowledge required, but it performs at an expert level.

Expert systems are continuing to be developed, usually without expectation of achieving true expert performance. Typically, they are being called knowledge-based systems, and are designed to function in a narrow range, or domain, and to provide accurate results within that domain. However, research in artificial intelligence and expert systems is continuing, and new developments should be expected.

3.3 EXPERT SYSTEMS FOR MATERIAL PROBLEMS. - Expert systems have been developed to perform material selection, diagnosis of material problems, failure analysis, material processing, life prediction, alloy development, etc. [14-22]. In general, many of these efforts have been abandoned due to a combination of their high cost, inability to achieve an expert level of performance, too broad or complex a problem, incompleteness of the knowledge, etc. Few expert systems have been developed for high-temperature attack and high-temperature coatings, especially as applied to gas turbines. Several expert systems for material problems are described below.

Expert systems have been successful and are in use in areas where expert performance is not required or where the knowledge can be sufficiently defined such that advanced, or even expert, performance is achievable. Less than expert performance is acceptable for programs that provide guidance or advice to a person not familiar with a specialized technology. An example would be in material selection in which an expert system can focus on several materials and eliminate many materials that are inappropriate for the application. Another example is a production line in which many of the potential problems can be anticipated and an expert system can be written for the operator to diagnose and solve the problem when it occurs.

3.4 ADVISOR ON BLADE COATINGS. - Advisor on Blade Coatings (ABC) is an expert system to select high-temperature coatings for industrial gas tubine blades [14] $\left({ }^{7}\right)$. The program is designed for utility engineers to use, and assumes that all they know is that they should consider a high-temperature coating for their blades.

The program runs under MS-DOS on a microcomputer with $640 \mathrm{kB}$ of memory, which greatly restricted the size and complexity of the program. The program was written in PROLOG primarily because it could be distributed without paying a royalty. PROLOG provided most of the tools needed, and those not available could be written, since PROLOG is essentially a full programming language.

The $A B C$ program is a rule-based system. Some rules are relatively simple, such as the

${ }^{7}$ ) This program was developed by Southwest Research Institute under EPRI funding. The author was the project manager, served as one of the knowledge engineers, and, eventually, as one of the experts. 
importance of high-temperature oxidation, which primarily depends on the metal temperature. Other rules, primarily involving the presence of hot corrosion, are complex because of the number of potential factors that must be considered, especially when many of the most important factors, such as air and fuel chemistry, are generally not known by utility engineers.

The user interface is a question-answer format that all users have found simple and easy to use. The answers are provided by means of a "consultation log" that gives the questions, the answers, the types of attack expected, the recommended coatings and the reasons for the recommendations.

The program works by asking a series of questions that determine the engine, type of operation and environmental factors. Depending upon the answers given, different questions may be asked. Once all the questions have been asked, the program determines the likely forms of high-temperature attack and the importance of fatigue. Based upon these determinations, the program recommends all coatings that provide adequate protection for this application. Generic coating classes are recommended instead of specific commercial coatings because of the large number and continual changes in coatings and vendors. It is the user's responsibility to choose a specific commercial coating and vendor, usually based upon economic factors and availability that are beyond the program's knowledge base.

Improvements planned for the program are increasing the number of engines and stages considered. Currently, the program does not account for the severity of attack by hot corrosion or for lower temperatures during part load operation. Including the degree of protection required and the level of protection offered by various coatings, along with a ranking of the coating's relative cost and potential life, will allow the program to optimize its choice of a coating. The author is developing mathematical models for coating degradation, and these will be included in the program as they become available.

3.5 ESCARTA. - ESCARTA is an expert system designed to determine the metallurgical cause of failure in boiler tubes used in electric utility boilers in large steam power plants [15], which is the primary cause of forced outages in these plants. ESCARTA is a rule-based system (forward chaining) written in $\mathrm{C}$ which runs on a DOS-based microcomputer. The program consists of about 500 rules that determine the 22 failure mechanisms found in boiler tubes. The program asks a series of questions to locate where the failure occurred, the operating parameters, and the appearance of the failure. A novel feature of the program is the use of a computer-driven slide viewer that shows the appearance of the different types of failure morphologies.

The program is in use at electric utilities, primarily by non-metallurgists and entry-level metallurgists. Experienced metallurgists do not use the program because they know as much or more than the program does. The program is useful for plant engineers to determine the probable cause of the failure, as well as to provide salient information to aid the failure analysis [23].

3.6 CORDIAL. - CORDIAL is an expert system to diagnose the causes of stress corrosion cracking (SCC) in 2000 and 7000 series aluminum alloys [16]. It was originally implemented on a Symbolics 3600 series computer using the KNOWLEDGE CRAFT integrated knowledge representation and problem-solving environment. The basis of the inferencing and evaluation procedures are from the PROSPECTOR-KAS system. It has also been implemented on a microcomputer using the $\mathrm{M} 1$ language.

The declarative knowledge is primarily material properties and manufacturing processes that can be found in handbooks and from manufacturers. The procedural knowledge is the rules used to diagnose SCC and is acquired from human experts. 
The diagnostic control engine is based upon about 165 rules designed to use a "depth-first" search strategy to determine the probability of various hypotheses, using Bayesian decision theory. The results of the analysis are reported with a confidence measure, but this measure was difficult for the user to interpret [24].

The system has been judged by a human expert as "reasons successfully at an elementary level". Significantly more effort is anticipated for the program to operate at an intermediate or advanced level. However, this project has been discontinued due to a lack of interest on the part of the company.

\section{Developing material data bases and expert systems.}

There are numerous approaches to the development of computer programs. Two of the most common ones are top down development and rapid prototyping [25]. Each approach is applicable for different types of programs and programming situations. With any approach, one can get into difficulty and overrun schedules and budgets, typically by a factor of two to three, because one cannot anticipate all the potential problems and requirements.

Top down development is the classical method of developing computer programs. With this approach, one carefully plans out the program by defining what the program is to do, how it is to do it, what the inputs and outputs are, the software and hardware to be used, how it is to be tested, etc., all before any computer code is written. Top down development is appropriate for well defined situations, such as those encountered in banks or retail stores. There is a United States military standard that defines this development process, which is similar to that used in designing a new machine.

The principal advantages of top down development are minimizing the time writing the program, knowing beforehand what the computer program will be, and forcing all parties involved to carefully think about the program. The principal disadvantage to this process is the difficulty in accommodating changes, because everything is so carefully defined beforehand. Changes occur because of needs that could not be anticipated, changes in direction by management, or because not all parties carefully thought through what they needed. Top down development is not recommended when key parts of the program cannot be defined beforehand.

Rapid prototyping is a method of developing computer programs when key parts of the program cannot be defined beforehand. It is particularly well suited when the end user cannot describe what is wanted, but says "I will know when it is right, when I see it." Rapid prototyping is characterized by the rapid development, evaluation and modification of a series of prototype programs that become successively better defined, more detailed and closer to what the end user wants. When done well, the process results in a program that the end user is happy with because it meets his needs and because he helped to develop the program. The $\mathrm{ABC}$ program discussed earlier was developed by a rapid prototyping process, which worked extremely well.

The cost and schedule of rapid prototyping is contained only if the computer code from earlier prototypes can be used in later prototypes. In principal, this method of program development is more expensive than that of top down development, but because it is designed to accommodate changes, whereas top down development is not, in the end it can be much less expensive and frustrating.

Rapid prototyping is the most appropriate process for developing expert systems because the expertise required cannot usually be defined beforehand. Also, expert systems will need to be modified to accommodate those questions, cases, and situations not originally antici- 
pated. Flat file and relational data bases can be developed by either approach, but hierarchical data bases must be developed by a top down approach because of the difficulty in making changes $\left({ }^{8}\right)$. However, it is the author's opinion that the rapid prototyping process is still preferable, because changes in the input data and output reports are usually unavoidable with engineering problems.

PROBLEM DEFINITION - THE KEY STEP - With either approach to program development, the most important step in the programming process is to first carefully define the problem. The program definition must include the inputs, the data processing and computations, the outputs, the hardware and software, the end user, and what the end user wants and needs. While this is de rigueur in the top down process, rapid prototyping must also begin with this information, but not to the same level of detail.

The most important part of this definition process is determining who the audience for the program is, and what that audience both wants and needs. This is so important because it is frequently overlooked, often with the disastrous consequence that the software is not used. The audience includes not only the people who will be actually using the computer program, but also their management, who will be evaluating the program and its effectiveness in their environment.

In the development of expert systems, it is necessary to identify several experts and to secure their cooperation. In the development of a data base, the most important initial step is to obtain the data, because it may be unavailable, of poor quality or of a different form than expected. Finally, in defining the programs for highly technical areas, especially those involving gas turbines, one may find the needed expertise or data is considered proprietary and not available, even within a private company. One must then determine what non-proprietary data or expertise is available, and whether it is of sufficient quality to warrant the time and expense of developing a computer program and its effectiveness in their environment.

The final recommendation concerning the development of computer programs considers changes in computer hardware, software and user interfaces, which occur at a two-to-threeyear cycle. Since expert systems and data bases can take at least two or more years to develop, test and deliver, one should anticipate the need to update the program to accommodate these changes. The real value of expert systems and data bases are their expertise and data, which change at a much slower pace, and will maintain their value.

\section{Summary.}

Coatings to resist high-temperature attack in gas turbine engines for aircraft, marine and industrial applications are mandatory to obtain the higher performance available from higher temperature operation. Frequently, the life of these coatings determines the maintenance interval of the hot section of the engine.

Computerization of information relevant to coatings and high-temperature attack is in its infancy. Despite considerable efforts in computerization of materials property information and some efforts in expert systems for materials, little has been done in the way of hightemperature attack and high-temperature coatings. Part of this difficulty is due to the difficulty of quantifying high-temperature attack and the performance of coatings, and part is due to the proprietary nature of much of the relevant information.

$\left({ }^{8}\right)$ If a data base programming language is used, these changes are usually easy. If a more general purpose language, such as FORTRAN or $\mathrm{G}$, is used, changes are much more difficult. 
The paper discusses material data bases and expert systems as applied to material problems. The principal difficulties of material data bases for test results on materials are completely describing the materials, their processing, the test conditions and the test results. Particularly time consuming is the evaluation of the quality of the test data. These problems are minimized for material data bases that report single-valued properties, such as obtained from handbooks.

Expert systems have, in general, failed to achieve expert performance. However, this does not preclude their usefulness since many material problems exist where people having less expertise than that of the expert system can benefit from the use of such a system. Several expert systems are described, including one to select high-temperature coatings for industrial gas turbines.

The development of material data bases and expert systems is best done by a rapid prototyping process instead of a traditional top down development process. This is due to the difficulty of defining all the inputs, outputs, knowledge and data before the program is written.

\section{References}

[1] BERNSTEIN H.L., ALLEN J.M., "A Review of High Temperature Coatings for Combustion Turbine Blades", to be published by EPRI in Proceedings of Steam and Combustion Turbine Blading Conference held (Jan. 1992).

[2] BERNSTEIN H.L., RuSSELl J.A., SCHEIRER S.T., HSU L.L., VAN ROODE M., Guidebook and Software for Specifying High-Temperature Coatings for Combustion Turbines, EPRI GS-7334-L, (EPRI, Palo Alto, CA, 1991).

[3] Ullman J.D., Principles of Database and Knowledge-Base Systems, (Computer Science Press, Rockville, MD, 1988).

[4] Computerization and Networking of Materials Databases, Glazman and Rumble Eds., ASTM STP 1017 (ASTM, Philadelphia, 1989).

[5] Computerization and Networking of Materials Databases: Second Volume, Kaufman and Glazman Eds. ASTM STP 1106 (ASTM, Philadelphia, 1991).

[6] Barry T., ReYnard K.W., Kaufman J.G., Third International Symposium on the Computerization and Use of Materials Property Data, (Cambridge, Sept. 1991) to be published as an ASTM STP.

[7] STREIFF R., KOMORNICKI S., Life Assessment \& Repair Technology for Combustion Turbine Hot Section Components, R. Viswanathan, J.M. Allen Eds. (ASM, Materials Park, OH 1990) p.245.

[8] LEVINE S.R., NASA TMX-2370 (1971).

[9] BERNSTEIN H.L., unpublished data.

[10] BarR A., Feigenbaum E.A., The Handbook of Artificial Intelligence (HeurisTech Press, Stanford, CA, 1981).

[11] WATERMAN D.A., A Guide to Expert Systems (Addison-Wesley, Reading, MA, 1986).

[12] BaChant J., MCDermotT J., AI Mag 5 (3) (1984).

[13] Duda R., hart P.E., NilsSON N.J., Barrett P., Gaschnig J.G., KonOlige K., RebOH R., SLOCUM J., "Development of the PROSPECTOR Consultation System for Mineral Exploration", Stanford Research Institute Report (Menlo Park, CA, 1978). 
[14] Fink P.K., Harloe E.D., Bernstein H.L., Russell J.A., Life Assessment \& Repair Technology for Combustion Turbine Hot Section Components, R. Viswanathan, J.M. Allen Eds. (ASM, Materials Park, OH, 1990) p. 239.

[15] SingH G.P., BAinS H.S., LAMPING G.A., Proceedings of Fossil Plant Inspections Conference, EPRI CS-5320, (EPRI, Palo Alto, CA, 1987) p. 2.49.

[16] BOAG W.A. Jr., REISER D.B., SPROWLS D.O., RYCHENER M.D., Artificial Intelligence Applications in Materials Science, R.J. Harrison, L.D. Roth Eds. (TMS-AIME, Warrendale, PA, 1986) p. 123.

[17] SRInivasan S., Kane R.D., Mater. Perform. (1990) 69.

[18] DARMODY M.P., COLlinS J.V., Artificial Intelligence Applications in Materials Science, R.J. Harrison, L.D. Roth Eds., (TMS-AIME, Warrendale, PA, 1986) p.175.

[19] Schreurs J., Pessall N., Adv. Mater. Proc. (1990) 63.

[20] Wright E.J., Westcott C., Williams D.E., Croall I.F., Mater. Design. 8 (3) (1987) 156.

[21] KOCH G.H., RineHART S.C., Mater. Perf. (1988) 49.

[22] Hoffelner W., ViTins M., High Temperature Materials for Power Engineering, E. Bachelet et al. Eds. (Kluwer, Boston, 1990) p.1599.

[23] BERnSTEIn, Private Communication with SINGH G.A., LAMPING G.A., (Mar 1992).

[24] BERnSTEIn, Private Communication with BOAG W.A. Jr. (Mar 1992).

[25] MetzGer Philip W., Managing a Programming Project, 2nd Edition, (Prentice-Hall, Englewood Cliffs, NJ, 1981). 